This item was submitted to Loughborough's Research Repository by the author.

Items in Figshare are protected by copyright, with all rights reserved, unless otherwise indicated.

\title{
Synthesis and characterization of divinyl-fumarate Poly- $\varepsilon$-caprolactone for scaffolds with controlled architectures
}

PLEASE CITE THE PUBLISHED VERSION

http://dx.doi.org/10.1002/term.2322

PUBLISHER

(c) Wiley

VERSION

AM (Accepted Manuscript)

\section{PUBLISHER STATEMENT}

This work is made available according to the conditions of the Creative Commons Attribution-NonCommercialNoDerivatives 4.0 International (CC BY-NC-ND 4.0) licence. Full details of this licence are available at: https://creativecommons.org/licenses/by-nc-nd/4.0/

\section{LICENCE}

CC BY-NC-ND 4.0

\section{REPOSITORY RECORD}

Ronca, A., Sara Ronca, Giuseppe Forte, S. Zeppetelli, A. Gloria, R. De Santis, and L. Ambrosio. 2016. "Synthesis and Characterization of Divinyl-fumarate Poly- $\varepsilon$-caprolactone for Scaffolds with Controlled Architectures". figshare. https://hdl.handle.net/2134/22831. 


\section{Tissue Engineering and Regenerative Medicine}

\section{Synthesis and characterization of divinyl-fumarate Poly- $\varepsilon-$ caprolactone for scaffolds with controlled architectures}

\begin{tabular}{|r|l|}
\hline Journal: & Journal of Tissue Engineering and Regenerative Medicine \\
\hline Manuscript ID & TERM-16-0098.R1 \\
\hline Wiley - Manuscript type: & Research Article \\
\hline Complete List of Authors: & $\begin{array}{l}\text { Ronca, Alfredo; Consiglio Nazionale delle Ricerche, Institute for Polymers, } \\
\text { Composites and Biomaterials } \\
\text { Ronca, Sara; Loughborough University, Department of Materials } \\
\text { Forte, Giuseppe; Loughborough University, Department of Materials } \\
\text { Zeppetelli, Stefania; National Research Council of Italy, Institute of } \\
\text { Polymers, Composites and Biomaterials } \\
\text { Gloria, Antonio; Consiglio Nazionale delle Ricerche, Institute for Polymers, } \\
\text { Composites and Biomaterials } \\
\text { De Santis, Roberto; Consiglio Nazionale delle Ricerche, Institute for } \\
\text { Polymers, Composites and Biomaterials } \\
\text { Ambrosio, Luigi; Consiglio Nazionale delle Ricerche, Department of } \\
\text { Chemical Sciences and Materials Technologies }\end{array}$ \\
\hline \hline Keywords: & $\begin{array}{l}\text { Photocrosslinkable polymer, Polycaprolactone fumarate, biocompatibility, } \\
\text { stereolithography, Cell-material interactions, mathematically defined } \\
\text { scaffolds }\end{array}$ \\
\hline \hline
\end{tabular}




\title{
Synthesis and characterization of divinyl-fumarate Poly- $\varepsilon$ - caprolactone for scaffolds with controlled architectures.
}

\author{
A. Ronca ${ }^{1}$, S. Ronca ${ }^{2}$, G. Forte ${ }^{2}$, S. Zeppetelli ${ }^{1}$, A. Gloria ${ }^{1}$, R. De Santis ${ }^{1}$ and L. \\ Ambrosio ${ }^{1,3}$ \\ ${ }^{1}$ Institute for Polymers, Composites and Biomaterials - National Research Council of \\ Italy, Mostra d'Oltremare Pad.20, Viale J.F. Kennedy 54, 80125 Napoli, Italy. \\ ${ }^{2}$ Department of Materials, Holywell Park, Loughborough University, Leicestershire, \\ UK, LE11 3TU \\ ${ }^{3}$ Department of Chemical Science and Materials Technology - National Research \\ Council of Italy, P.le Aldo Moro, 7 - 00185 Roma, Italy.
}

\begin{abstract}
A vinyl-terminated Polycaprolactone has been developed for tissue engineering applications using a one-step synthesis and functionalization method based on Ring Opening Polymerization (ROP) of $\varepsilon$-caprolactone, with Hydroxyl Ethyl Vinyl Ether (HEVE) acting both as the initiator of ROP and as photo-curable functional group. The proposed method employs a catalyst based on Al, instead of the most popular Tin(II) 2-ethylhexanoate, to reduce the cytotoxicity. Following the synthesis of the vinyl-terminated polycaprolactone, its reaction with Fumaryl Chloride $(\mathrm{FuCl})$ results in a divinyl-fumarate polycaprolactone (VPCLF). The obtained polymers were thoroughly characterized using Fourier Transform Infrared Spectroscopy (FTIR) and gel permeation chromatography (GPC) techniques. The polymer has been successfully employed, in combination with N-vinyl Pyrrolidone (NVP), to fabricate films and computer-designed porous scaffolds by micro-stereolithography ( $\mu$-SL) with Gyroid and Diamond architectures. Characterization of the networks indicated the influence of NVP content on the network properties. Human Mesenchymal Stem Cells (hMSCs) adhered and spread onto VPCLF/NVP networks showing good biological properties and no cytotoxic effect.
\end{abstract}

Keywords: Photocrosslinkable polymer, Polycaprolactone fumarate, biocompatibility, stereolithography, cell-material interactions, mathematically defined scaffold.

\section{Introduction}

Tissue engineering can provide a way to regenerate damaged tissue (Park et al., 2012; Guarino et al., 2012 a; Catauro et al., 2007). One of the most important considerations in tissue engineering is the scaffold used to provide support to the cells and to regulate cell biology and development into complex three-dimensional (3D) structures (Dhariwala et al., 2004, Ronca et al., 2013; Gloria et al., 2009). RP, also known as Solid Freeform Fabrication, is a group of techniques that creates 3D objects through repetitive deposition and processing of material layers using computer-controlled equipment (Yeong et al., 2004; De Santis et al., 2013; De Santis et al., 2011). Rapid prototyping 
technologies and computer-aided design (CAD) enable the precise control over pore geometry and the design of $3 \mathrm{D}$ structures for the preparation of tissue engineering scaffolds (Eloma et al., 2013; Guarino et al., 2012 b). Among the rapid prototyping techniques, stereolithography represent the most versatile method providing the highest precision and accurancy (Ronca et al., 2012). The key principle of stereolithography is the spatially controlled solidification of a photo-polymerizable resin. Using a computercontrolled laser beam or digital light projection, and a computer-driven support platform, 3D object can be manufactured in a layer-by-layer manner (Melchels et al., 209; Sun et al., 2005). By projecting a two-dimensional pixel-pattern through a transparent plate, a complete layer of resin can be cured at once according to complex plane pattern. (Pham et al., 1998;. Most of the available resin are based on lowmolecular weight, acrylate monomers (Ronca et al., 2013; Eloma et al., 2013, Melchels et al., 2010). These materials are predominantly glassy, rigid and brittle. Only few resins have been described that allow the preparation of elastomeric objects by stereolithography (Bens et al., 2007). The functionalization of aliphatic polyesters, such as Polyglycolide (PGA), Polylactide (PLA), Poly ( $\varepsilon$-caprolactone) (PCL), with unsaturated groups and subsequent Ultraviolet (UV) crosslinking has been introduced to overcome this limitation (Grijpma et al., 2005; Sawhney et al., 1993). Photo-curable functional groups, such as methacrylate have been used most often as unsaturated group attached on precursor oligomers (Liow et al., 2009; Storey et al., 1993). However, the diffusion of unpolymerized methacrylates is one of the most important factors causing irritation in tissues (Yoshii et al., 1997; De Santis et al., 2010). Many studies have found that substances leached out from acrylic resin can cause, inflammation, or even an allergic reaction (Jorge et al., 2003; Kedjarune et al., 1999). To overcome these problems, we are investigating an alternative divinyl-fumarate PCL expected to have a lower level of toxicity and skin sensitization as compared to acrylate (Blyler et al., 1999). Synthesis and vinyl functionalization can be achieved in one step, by using ring opening polymerization (ROP). Hydroxyethyl Vinyl Ether (HEVE) was employed to play the role of the ROP initiator, and to introduce a photo-curable vinyl functional group (Lioe et al., 2009). A subsequent reaction with fumaric acid allows the introduction of a fumarate group, in order to have a tri-functional macromer suitable for UV curing (Grijpma et al., 2005). The most common initiator for ROP of $\varepsilon$-CL is Stannous Octanoate $\mathrm{Sn}(\mathrm{Oct})_{2}$. Although very efficient, its cytotoxicity has recently caused deep concern about biosafety of the materials synthesized from it and used for implantation purpose (Albertsson et al., 2000; Kricheldorf et al., 2000). In this work, a $\mathrm{Sn}$-free catalyst based on Al has been used in the polymerization of CL achieving more than 95\% monomer conversion at room temperature (Akatsuka et al., 1995). In addition to chemical-physical characterization, in vitro cytotoxicity and biocompatibility of the crosslinked materials in direct contact with human mesenchymal stem cells (hMSCs) were also studied, to validate the potential utility of this innovative tri-functional polymer in tissue engineering applications. 


\section{Materials and methods}

\subsection{Materials}

All manipulations of both air and moisture sensitive compounds were performed under a protective atmosphere (nitrogen or argon) using Schlenck techniques or in a glove box. $\varepsilon$-Caprolactone ( $\varepsilon$-CL) was purchased from Aldrich and further dried before use by $4 \AA$ molecular sieves. Dichloromethane dry was purchased from Aldrich and used as received. The Al catalyst was prepared by reacting Trimethylaluminum $(10 \%$ weight solution in toluene) with 2 equivalents of 2,6-ditert-butyl-4-methylphenol (both reagents purchased from Aldrich). N-Methyl-2-Pyrrolidone (NMP) and N-VinylPyrrolidone (NVP) were purchased from Sigma-Aldrich (The Netherlands) and employed without further purification. The UV photoinitiator Lucirin TPO-L (ethyl2,4,6-trimethyl-benzoylphenylphosphinate) was a gift from BASF, Germany.

\subsection{Synthesis of divinyl fumarate}

A Sn-free catalyst based on Al has been used in the polymerization of $\varepsilon$-CL at room temperature, similarly to the procedure described by Liow et al., with the modification of the initiator used. Here the 2-Hydroxyethyl Vinyl Ether (HEVE) as photocurable initiator has been used (Liow et al., 2009). The polymerization reaction was performed in a Schlenk tube under a nitrogen atmosphere, at room temperature overnight under magnetic stirring, then quenched by addition of methanol. The precipitated PCL was filtered out, washed with further methanol and dried in a vacuum oven overnight at $40^{\circ} \mathrm{C}$. After the synthesis of the vinyl-terminated PCL (VPCL, Mw $=1.5 \mathrm{kDa}$ ), the polymer was reacted with fumaryl chloride, resulting in a divinyl-fumarate polycaprolactone. As showed in Figure 1 the chains contain three photocrosslinkable vinyl units: two at the ends and one in the middle of the chain. By adjusting the $\varepsilon$-CL to HEVE ratio, the number average molecular weight $M_{\mathrm{n}}$ of the vinyl precursor could be easily controlled to achieve a range between 2000 and $5000 \mathrm{~g} / \mathrm{mol}$. Three different molecular weights (namely as VPCLA, VPCLB and VPCLC) and one divinyl fumarate polycaprolactone (VPCLF) were achieved as reported in Table 1. Lower molar weight PCL (1.5kDa, VPCLC) was used for the fumarate reaction, this choice was driven by the requirement of a low viscosity suitable for the stereolithographic process.

\subsection{Characterization of divinyl-fumarate polycaprolactone macromers}

2.3.1. Gel permeation chromatography $(G P C)$. The synthesized VPCLX (where X represent A, B and C) and VPCLF macromers were characterized with respect to molecular weight and molecular weight distribution by Gel Permeation Chromatography (GPC) in THF solution $(1 \mathrm{mg} / \mathrm{ml})$ at room temperature using a GPC/SEC (Agilent Technologies 1260 Infinity).

2.3.2. Fourier transform infrared spectroscopy (FTIR). Fourier transform infrared (FTIR) spectroscopy (Nicolet 5700, FTIR spectrometer ) was implemented to identify 
the functional groups of VPCLX. KBr disks was realized using $2 \mathrm{mg}$ of polymer powder compacted with $200 \mathrm{mg}$ of $\mathrm{KBr}$ in a hydraulic press. Spectra were recorded in the $400-4000 \mathrm{~cm}^{-1}$ region ( $4 \mathrm{~cm}^{-1}$ resolution, averaging 64 scans).

2.3.3. Differential scanning calorimetry (DSC). Thermal properties were evaluated by Differential Scanning Calorimetry (DSC - TA Instrument Q1000). The specimens (8-10 $\mathrm{mg}$ ) were heated from $30^{\circ} \mathrm{C}$ to $80^{\circ} \mathrm{C}$ at $10^{\circ} \mathrm{C} / \mathrm{min}$, cooled from $80^{\circ} \mathrm{C}$ to $-80^{\circ} \mathrm{C}$ at $10^{\circ} \mathrm{C} / \mathrm{min}$ and then re-heated up to $80^{\circ} \mathrm{C}$ at $10^{\circ} \mathrm{C} / \mathrm{min}$. Melting temperatures were calculated from the second heating scan and reported in Table 1.

2.3.4. Photodifferential scanning calorimeter ( $p D S C$ ). Q1000 (TA Instruments Waters LLC, New Castle, DE, USA) was used to investigate the kinetics of photopolymerization of functional group present in VPCLX and VPCLF. Pulverized VPCLX and VPCLF were dissolved in two solvents; non-photoreactive NMP and photoreactive NVP respectively. The UV light source was a $200 \mathrm{~W}$ high pressure mercury lamp, providing a wavelength spectrum range of 250-650 nm. Prior to the UV exposure samples were subjected to 5 minute isothermal treatment at $60^{\circ} \mathrm{C}$. A nitrogen flux of $50 \mathrm{~cm}^{3} / \mathrm{min}$ assured homogeneity of temperature distribution in the measuring cell. Photocurable polymer $(3 \pm 1 \mathrm{mg})$ were placed in open aluminum pans and they were exposed to UV light intensity of $50 \mathrm{~mW} / \mathrm{cm}^{2}$ for 15 minutes at constant temperature of $60^{\circ} \mathrm{C}$.

\subsection{Photo-crosslinking of divinyl-fumarate macromers}

The reactivity of divinyl-fumarate macromers is significantly lower if compared to acrylate-functionalized oligomers, and N-Vinyl Pyrrolidone (NVP) is usually used as a crosslinking agent (Dome et al., 1991; He et al., 2001]. Networks were formed from VPCLF by UV irradiation (365 nm) and a biocompatible initiator (Lucirin TPO).

The NVP content was varied from 30 to $50 \mathrm{wt} \%$ and the influence of NVP on the network was evaluated. Briefly $5 \mathrm{wt} \%$ of Lucirin TPO (relative to macromers) was dissolved in the desired amount of NVP by magnetic stirring and then the VPCLC-F macromers were added to the solution. The mixture was placed in an oven at $50-60{ }^{\circ} \mathrm{C}$ in order to completely dissolve the macromers. The reactive solution was poured in a Teflon mold and irradiated by UV light for $30 \mathrm{~min}$ at a distance of $5 \mathrm{~cm}$. Diluent, unreacted macromers, $\mathrm{t}$ and photoinitiator were extracted from the crosslinked network using water and a 3:1 ( vol/vol) mixture of isopropanol and acetone. The films were then dried in oven at $60^{\circ} \mathrm{C}$ for 1 day under vacuum.

\subsection{Gel content and water uptake}

Gel content studies were performed using Tetrahydrofuran (THF). To determine the gel content of the prepared networks, VPCLF/NVP disk specimens $(\Phi=6 \mathrm{~mm}, \mathrm{~h}=2 \mathrm{~mm})$ were weighed $\left(\mathrm{m}_{0}\right)$, they were placed into $50 \mathrm{ml}$ THF for 2 days and then dried and weighed again $\left(\mathrm{m}_{1}\right)$. The gel content was defined as: 
For water uptake measurements, specimens of extracted networks $(n=4)$ were weighed $\left(\mathrm{m}_{\mathrm{d}}\right)$ and equilibrated in distilled water for 1 day at $37^{\circ} \mathrm{C}$. The samples were removed from the water, blotted dry, and weighed again $\left(\mathrm{m}_{\mathrm{s}}\right)$. The water uptake was calculated using the following equation:

$$
\text { Water uptake }=\frac{\left(m_{s}-m_{d}\right)}{m_{d}} \times 100
$$

\subsection{Biological characterization}

2.6.1. hMSC expansion, seeding and culture. Biological assays were carried out using human mesenchymal stem cells line (hMSCs, LONZA, Milano, Italy). hMSCs were cultured in $75 \mathrm{~cm}^{2}$ cell culture flask in Eagle's alpha Minimum Essential Medium ( $\alpha$ MEM) supplemented with $10 \%$ fetal bovine serum (FBS), antibiotic solution (streptomycin $100 \mathrm{mg} / \mathrm{mL}$ and penicillin $100 \mathrm{U} / \mathrm{mL}$, Sigma Chem), and $2 \mathrm{mM} \mathrm{L}-$ glutamine. hMSCs from passages 4 through 6 passage were incubated at $37^{\circ} \mathrm{C}$ with $5 \%$ $\mathrm{CO}_{2}$ and $95 \%$ air. VPCLF/NVP disk specimens $(\Phi=6 \mathrm{~mm}, \mathrm{~h}=2 \mathrm{~mm})$ were cut from photocrosslinked films and were prepared for cell seeding by first soaking in $70 \%$ ethanol (1h) and then $1 \%$ antibiotic/antimycotic in phosphate-buffered saline (PBS) $(2 \mathrm{~h})$, and pre-wetting in medium ( $2 \mathrm{~h}$ ). $15 \times 10^{4}$ cells, re-suspended in $50 \mu \mathrm{l}$ of medium, were statically seeded onto the scaffold. After seeding, the scaffolds were placed in 48well culture plates ( 1 scaffold per well) and, incubated for $2 \mathrm{~h}$ in a humidified atmosphere $\left(37{ }^{\circ} \mathrm{C}, 5 \% \mathrm{CO}_{2}\right)$. After the initial $2 \mathrm{~h}$ for cell attachment to the pre-wetted scaffolds $1.5 \mathrm{ml}$ of cell culture medium was added. Scaffolds were maintained in culture for 2 day. Successively, the materials were rinsed twice with PBS, culture medium and unattached cells were removed. The remaining cells were then fixed using formalin (4\% formaldehyde in water) for $15 \mathrm{~min}$ and then washed with PBS. The samples were stained with hematoxylin and washed twice in distilled water. Cell morphology spreading pattern interaction of hMSC onto VPCLF/NVP specimens were evaluated by confocal laser scanning microscopy (LSM 510, Carl Zeiss).

2.6.2. Alamar blue assay. Cell viability and proliferation were evaluated by the Alamar blue assay. Such technique is based on a redox reaction that occurs in the cytosol of the cells and quantifies the redox indicator which changed to a fluorescent product in response to the chemical reduction by mitochondrial enzymes such as flavin mononucleotide dehydrogenase, flavin adenine dinucleotide dehydrogenase, and nicotinamide adenine dinucleotide dehydrogenase. Furthermore a redox phenomenon gave a quantitative indication of metabolic activity of live cells. The cell-scaffold constructs were removed from the culture plates at days 1,7,10 and 14, rinsed with PBS 
(HyClone, UK) and placed in 48-well culture plates. $1 \mathrm{~mL}$ of alamar blue diluted 1:10 in phenol red-free medium was added to each well and incubated for a further $4 \mathrm{~h}$ at $37^{\circ} \mathrm{C}$, $5 \% \mathrm{CO}_{2}$. Successively, $200 \mu \mathrm{L}$ of this solution was transferred into a 96 well plate for the colorimetric analysis. Wells without any cells were used to correct any background interference from the redox indicator. The optical density was measured with a spectrophotometer (Victor X3, PerkinElmer, Massachusetts, USA) at wavelengths of 540 and $600 \mathrm{~nm}$. The number of viable cells is correlated with the level of dye reduction and it is expressed as "percentage of reduction" (\%AB reduction), according to the manufacturer's protocol. Moreover, the number of viable cells on the 2D support was determined by comparing the absorbance at different culture times with a calibration curve obtained by correlating known cell numbers in the 24 -well culture plates with the corresponding absorbance values. The culture medium was changed every two days.

\subsection{Mathematically defined scaffolds}

Stereolithography is a layer-by-layer fabrication method. Complex structures can be built by illuminating sequential layers of a polymerizable resin using digital pixel masks or arrays of mirrors Lucirn TPO-L photo-initiator (5 wt $\%$ ) and Orasol Orange G dye $(0.1 \mathrm{wt} \%)$ were added to a solution containing $50 \mathrm{wt} \%$ VPCLF and $50 \mathrm{wt} \% \mathrm{NVP}$. This resin was used to prepare porous structures by stereolithography with a commercially available set-up (Perfactory Mini Multilens, EnvisionTec). In order to design a suitable scaffold for tissue engineering our approach was to use the family of Triply Periodic Minimal Surfaces (TMPS) as pore morphology. This advanced approach consists on designing sophisticated 3D porous structures using the periodicity of trigonometric equations. The idea was to try to simulate the complex design of models frequently encountered in the nature such as minimal surface architecture (Melchels et al., 2010). In addition, TMPS based scaffolds offer high porosity and pore interconnection that might be beneficial for tissue regeneration independently of the scaffold complexity (Yoo et al., 2011; Rajagopalan et al., 2006). K3DSurf software (http://k3dsurf.sourceforge.net) was employed to generate CAD-files describing the surfaces of Gyroid (G) and Diamond (D) architectures (Gandy et al., 2000; Gandy et al., 1999). The following trigonometric functions with boundary conditions $x, y=[-6 \pi, 6 \pi]$ and $\mathrm{z}=[-3 \pi, 3 \pi]$ were used:

$$
\begin{gathered}
G: \cos (x) \cdot \sin (y)+\cos (y) \cdot \sin (z)+\cos (z) \cdot \sin (x)=C \\
D: \sin (x) \cdot \sin (y) \cdot \sin (z)+\sin (x) \cdot \cos (y) \cdot \cos (z)+\cos (x) \cdot \sin (y) \cdot \cos (z) \\
+\cos (x) \cdot \cos (y) \cdot \cos (z)=C
\end{gathered}
$$

To develop porous structures with a porosity of approximately 50-60\%, offset values (C) of 0.5 and 0.2 are required for Gyroid and Diamond architectures, respectively. Then, all CAD files were converted to STL files and sliced into 2D sections, each 
having $25 \mu \mathrm{m}$ layer thickness, through the Envisiontec Perfactory RP 2.0 software. At the end of the fabrication process uncured resin were removed with Acetone and the scaffolds were postcured in oven at $90^{\circ} \mathrm{C}$ for $24 \mathrm{~h}$ under vacuum.

\subsection{Morphological characterization of scaffolds}

Scanning electron microscopy (SEM) was performed to obtain qualitative information related to the morphology and pore characteristics of the manufactured VPCLF/NVP structures. The specimens were gold sputtered and observed with a FEI QUANTA 200 FEG scanning electron microscope. As nondestructive structural analysis, microcomputed tomography ( $\mu$-CT) was performed using a SkyScan 1172 micro-CT scanner (Bruker) at $5.45 \mu \mathrm{m}$ resolution. Scaffolds were mounted on a rotary stage and were scanned at an X-ray tube voltage of $59 \mathrm{kV}$, a current of $167 \mu \mathrm{A}$ and a rotation angle of $180^{\circ}$. A two-dimensional (2D) detector records projections of the sample for different angular positions. For the present study 1187 projections within an angular range of 180 were taken. The exposure time was $200 \mathrm{~ms}$ per projection. The images were recorded on a $20482048 \mathrm{CCD}$ detector, with the pixel size set to $5.45 \mu \mathrm{m}$. The 3D structure was finally reconstructed using a filtered back-projection algorithm. A volume of interest was reconstructed for each sample; a single voxel of the reconstructed image had a size of $5.45 \times 5.45 \times 5.45 \mu \mathrm{m}^{3}$. SkyScan CT-analyzer biomedical image software were used to generate $3 \mathrm{D}$ images to show the distribution of phases.

\section{Results and discussions}

In this work we synthesized a tri-functional photocrosslinkable PCL by using HEVE in the presence of a novel Sn-free catalyst based on Al. The resulting divinyl-fumarate PCL network was characterized by its molar weights, functional end groups and transition temperatures, using several techniques including GPC, NMR, FTIR, DSC and $p \mathrm{DSC}$.

\subsection{Synthesis of divinyl fumarate $P C L$}

The polymerization of $\varepsilon$-caprolactone with the methylaluminum bis(2,6 ditertbutyl-4methylphenolate) system proceeded smoothly at room temperature to give a polyester showing a reasonably narrow molecular weight distribution (MWD). To enable photocuring of PCL, a monofunctional vinyl ether was incorporated into each PCL chain. The resulting polymers, isolated by pouring the polymerization mixture into $\mathrm{MeOH} / \mathrm{H}_{2} \mathrm{O}$ solution (50/50 vol/vol), had an $\mathrm{M}_{\mathrm{w}} / \mathrm{M}_{\mathrm{n}}$ ratio that varied from 1.31 for the VPCLA to the 1.48 of the VPCLB. Also the $M_{n}$ measurements closely matched the theoretical values $\left(\mathrm{M}_{\mathrm{n}, \text { theo }}\right)$ as it is shown in Table 1 . PCL with a range of molecular weight ranging from 1.5 - $6 \mathrm{kDa}$ were successfully synthesized but only the lower molar weight PCL (1.5kDa, VPCLC) was used for the following fumarate reaction. Low molar weight vinyl-PCL was reacted with fumaryl chloride to obtain a tri-functional photocurable polycaprolactone. The FTIR spectra of VPCL before and after the reaction with fumaryl chloride are shown in Figure 2. The absorption bands with peaks 
positioned at 2947 and $2866 \mathrm{~cm}^{-1}$, a common feature of VPCL and VPCLF spectra, are due to the stretching of the methylene groups $\left(\mathrm{CH}_{2}\right)$ of PCL. The absorption band at $1730 \mathrm{~cm}^{-1}$ is due to the carbonyl $(\mathrm{C}=\mathrm{O})$ vibration of PCL and fumarate. This band is stronger in the VPCLF spectrum because the carbonyl groups of PCL, as well as those of fumaryl chloride, contribute to the absorption band. The weak absorption bands with peak positions at 1240 and $1367 \mathrm{~cm}^{-1}$ are due to the $\mathrm{C}-\mathrm{H}$ rocking vibration of the disubstituted fumarate group while the peak at $1646 \mathrm{~cm}^{-1}$ is due to $\mathrm{C}=\mathrm{C}$ stretching. A relatively strong absorption band with the peak positioned at $1171 \mathrm{~cm}^{-1}$, evident in VPCLA and VPCLF spectra, is due to asymmetric coupled vibrations of $\mathrm{C}-\mathrm{C}(=\mathrm{O})-\mathrm{O}$ and O-C-C groups of VPCL. The melting temperatures $\left(\mathrm{T}_{\mathrm{m}}\right)$ of the macromers were determined by DSC and are presented in Figure 3. DSC analysis shows the dependence of the melting temperature $\mathrm{Tg}$ as a function of average molecular weight of the macromers. The melting temperature increases progressively by increasing molecular weight. Between $\mathrm{Mn}=2300 \mathrm{Da}$ and $\mathrm{Mn}=6800 \mathrm{Da}$ the melting temperature rises from $50.84^{\circ} \mathrm{C}$ to $53.61^{\circ} \mathrm{C}$.

\subsection{Photocrosslinking of VPCLF macromers}

Photocuring of the VPCL and VPCLF has been performed using two sets of samples by dissolving macromers in NMP (non-reactive solvent) and NVP (reactive solvent) respectively, in presence of a biocompatible UV photo-initiator (Lucirin TPO). Upon UV exposure, polymerization of double bonds leads to formation of linearly grafted PCL. The use of NVP as a crosslinking agent significantly increases the cross-linking rates as it is possible to see from PCA analysis (Table 2). Low reactivity of the system is further confirmed by long induction time and low rate coefficients $(\mathrm{k})$, as compared to the NVP system. High reactivity of the VPCL/NVP system is further corroborated by the lower induction time and higher rate coefficient $(\mathrm{k})$, as it is showed in Table 2. Application of reactive diluent was necessary due to the significantly lower reactivity of synthesized VPCL and VPCLF in comparison with acrylate-functionalized ones. Up to now NVP is preferable to the other small monomers (like acrylic or methacrylic acid) due to the more solubility and biocompatibility of the monomers and degradation products of the system.

\subsection{Characterization of VPCLF/NVP network}

Although VPCLF has the capability of being crosslinked, its polymerization reaction is very slow and results in a putty-like material after $20 \mathrm{~min}$ of irradiation. This behavior is probably due to the lack of enough double bonds or steric hindrance of fumarate double bonds along the VPCLF backbone, which restricts the movement of macro radicals leading to a decrease in maximum double bond conversion. Adding NVP may facilitate the crosslinking reaction, since NVP bridges adjacent VPCLF chains. Using UV irradiation (365 $\mathrm{nm}$ ) and a biocompatible photo-initiator such as Lucirin TPO, networks were formed from VPCLF macromers and NVP. The network properties were assessed by varying the NVP content from 30 to $50 \mathrm{wt} \%$. After curing for $20 \mathrm{~min}$, the 
gel content of the networks was above $85 \%$ in all samples. The NVP-containing VPCLF networks absorb significantly more water as it is possible to notice from Figure 4. As a consequence of the hydrophilic character of NVP, the water uptake increases by increasing the NVP content.

\subsection{Cell Adhesion to VPCLF/NVP Networks}

To assess the suitability of these networks for cell culturing and tissue engineering, initial cell adhesion experiments were performed. The cellular attachment is the first step in evaluating the biocompatibility of hMSC onto the VPCLF material. Figure 5 illustrates the confocal images of hMSCs cellular onto crosslinked material after 1 day of cell culture. Tissue culture polystyrene (TCPS) was used as a positive control (Ctr). It is worth noting that the hMSCs cells adhered well to the VPCLF/NVP networks, presenting a spread morphology and this representative morphology is a positive sign that cells have a good biocompatibility and affinity for the VPCLF/NVP materials. Even though it seems that the cells had a slightly higher tendency to aggregate on the networks with the highest NVP contents, the results indicate good cell adhesion for all the range of VPCLF/NVP networks investigated. Cell proliferation is assessed by alamar blue as shown in Figure 6. For all materials, confluency was reached within 14 days. Our results demonstrated that the materials appeared not to be cytotoxic neither show a negative response to cell adhesion. This confirms that VPCLF/NVP films are suitable substrates for cell culturing.

\subsection{Mathematically defined scaffolds}

The photochemical and biological features of the developed networks encourage their application in the field of tissue engineering. Accordingly, we studied the possibility of developing porous structures from VPCLF/NVP 50/50 formulations by stereolithography. The VPCLF/NVP resins (also containing $5 \mathrm{wt} \%$ Lucirin-TPO, and $0.1 \mathrm{wt} \%$ Orange Orasol G) were first analyzed with respect to their photocuring behavior in the stereolithography apparatus. We developed porous VPLCF/NVP network scaffolds with mathematically defined architectures characterized by high pore interconnectivity and specific surface area and they are presented Figure 7. Such features make it an appropriate structures for tissue engineering, since it favors cellseeding at high densities, also allowing homogeneous cell distribution and flow of nutrients throughout the scaffold. Structural parameters such as porosities, pore sizes and specific surface areas can be evaluated from $\mu \mathrm{CT}$ data. The designed architectural features are preserved and porosity is almost unaffected by the fabrication process as it is possible to notice from Table 3. Early literature suggests a minimum recommended pore size for a scaffold of $100 \mu \mathrm{m}$, but recent studies have shown better osteogenesis for implants with pores size higher than $300 \mu \mathrm{m}$ (Karageorgiou et al., 2005; Hulbert et al., 1970). Relatively larger pores favor direct osteogenesis, since they allow vascularization and high oxygenation, while smaller pores result in osteochondral ossification, although the type of bone ingrowth depends on the biomaterial and the geometry of the pores (Kuboki et al., 2001; Ayers et al., 1999). The porous structures were analyzed by micro- 
computed tomography $(\mu \mathrm{CT})$ and results were reported in Figure 8. As a result of the regularity of the design and the precision of the employed building technique, the histogram shows a narrow pore size distribution for both architectures. The average pore size was $400 \mu \mathrm{m}$ for the Diamond and $710 \mu \mathrm{m}$ for the Gyroid. From the $\mu \mathrm{CT}$ data a porosity of $64 \%$ and $58 \%$ was determined for Gyroid and Diamond structure respectively, while the porosity of the designed architectures was $66 \%$ for the Gyroid and $59 \%$ for the Diamond. These results clearly show the suitability of the proposed materials to create porous structures with narrow pore size distributions and high pore interconnectivities by stereolithography.

\section{Conclusions}

In this article a novel approach to synthetize a divinyl fumarate Polycaprolactone that can be used to manufacture tissue engineering scaffolds by stereolithography has been investigated. A non-toxic, Al-based catalyst was used for the polymerization of CL, to avoid the use of potentially cytotoxic Sn (Oct) 2 . Hydroxyethyl Vinyl Ether (HEVE) was employed as ROP initiator to introduce a photo-curable vinyl functional group at the beginning of the chain, while fumaric acid was added to the PCL oligomer to obtain a tri-functional UV curable resin. Photopolymerization kinetic of the resulting materials (with and without fumaric group) was studied in both NMP and NVP solution using Lucirin TPO as radical photoiniziator. The best results were obtained when using a reactive solvent, such as NVP. The resins were successfully employed to build complex 3D structures based on Gyroid and Diamond architectures, with high interconnectivity and porosity. The versatility provided by stereolithography technique will allow the fabrication of implants with different porosities, pore sizes and morphology that can mimic the complex architecture of tissue-specific sites. Human Mesenchymal Stem Cells, seeded on scaffolds prepared from VPCLF/NVP resin, were spread on the surface after $24 \mathrm{~h}$ and formed a confluent cell layer. Results suggest that VPCLF/NVP macromers is potentially useful as a cross-linkable material for tissue regeneration.

\section{References}

Akatsuka M, Aida T, Inoue S. 1995; Alcohol/methylaluminum diphenolate systems as novel, versatile initiators for synthesis of narrow molecular weight distribution polyester and polycarbonate. Macromolecules 28: 1320-22.

Albertsson AC, Edlund U, Stridsberg K. 2000; Controlled ring-opening polymerization of lactones and lactides. Macromol. Symp. 157: 39-46.

Ayers RA, Simske SJ, Bateman TA et al. 1999: Effect of nitinol implant porosity on cranial bone ingrowth and apposition after 6 weeks. J Biomed. Mater. Res. 45: 42-7.

Bens, A, Seitz H, Bermes G et al. 2007; Non-toxic flexible photopolymers for medical stereolithography technology. Rapid Prototyping J. 13: 38-47.

Blyler LL, Paczkowski MA, Simoff DA et al. 1999; Vinyl ether terminated oligomers and polymers U.S. Patent 5989627, USA. 
Catauro M, Raucci MG, Ausanio G et al. 2007; Sol-gel synthesis, characterization and bioactivity of poly (ether-imide) $/ \mathrm{TiO}_{2}$ hybrid materials. J. appl biomater. biom. 5: 4148.

De Santis R, Gloria A, Prisco D et al. 2010; Fast curing of restorative materials through the soft light energy release. Dent Mater. 26: 891-900.

De Santis R, Gloria A, Russo T et al. 2011; A basic approach toward the development of nanocomposite magnetic scaffolds for advanced bone tissue engineering. J. Appl. Polym. Sci. 122: 3599-05.

De Santis R, Gloria A, Russo T et al. 2013; Advanced composites for hard-tissue engineering based on PCL/organic-inorganic hybrid fillers: From the design of 2D substrates to 3D rapid prototyped scaffolds. Poly. Composites 34: 1413-17.

Dhariwala B, Hunt E, Boland T. 2004; Rapid prototyping of tissue-engineering constructs, using photopolymerizable hydrogels and stereolithography. Tissue engineering 10: 1316-22.

Domb AJ, Mathiowitz E, Ron E et al. 1991; Polyanhydrides IV. Unsaturated and crosslinked polyanhydrides. J. Polym. Sci. A Polym. Chem. Edn. 29: 571-79.

Eloma L, Kokkari A, Närhi T et al. 2013; Porous 3D modeled scaffolds of bioactive glass and photocrosslinkable poly(e-caprolactone) by stereolithography. Compos. Sci. Technol. 74: 99-106.

Gandy PJF, Klinowski 2000; J Schwarz meets Schwann: Design and fabrication of biomorphic and durataxic tissue engineering scaffolds. Chem. Phys. Lett. 321: 363-71.

Gandy PJF, Cvijovic D, Mackay AL et al. 1999; J Exact computation of the triply periodic D ('diamond') minimal surface. Chem. Phys. Lett. 314: 543-51.

Gloria A, Russo T, De Santis_R et al. 2009; 3D fiber deposition technique to make multifunctional and tailor-made scaffolds for tissue engineering applications. $J A B B$ 7: 141-52.

Grijpma DW, Hou Q, Feijen J. 2005; Preparation of biodegradable networks by photocrosslinking lactide, $\varepsilon$-caprolactone and trimethylene carbonate-based oligomers functionalized with fumaric acid monoethyl este Biomaterials 26: 2795-02.

Guarino V, Gloria A, Raucci MG et al. 2012 a; Hydrogel-based platforms for the regeneration of osteochondral tissue and intervertebral disc. Polymers 4: 1590-12.

Guarino V, Gloria A, Raucci MG et al. 2012 b; Bio-inspired composite and cell instructive platforms for bone regeneration. Int. Mater. Rev. 57: 256-275.

He S, Timmer MD, Yaszemski MJ et al. 2001; Synthesis of biodegradable poly(propylene fumarate) networks with poly(propylene fumarate)-diacrylate macromers as crosslinking agents and characterization of their degradation products Polymer 42: 1251-60.

Hulbert SF, Young FA, Mathews RS et al. 1970; Potential of ceramic materials as permanently implantable skeletal prostheses. J Biomed. Mater. Res. 4: 433-56.

Jorge JH, Giampaolo ET, Machado AL et al. 2003; Cytotoxicity of denture base acrylic resins: a literature review. J. Prost. Den. 90: 190-93. 
Karageorgiou V, Kaplan D. 2005; Porosity of 3D biomaterial scaffolds and osteogenesis Biomaterials 26: 5474-91.

Kedjarune U, Charoenworaluk N, Koontongkaew S. 1999; Release of methyl methacrylate from heat-cured and autopolymerized resins: cytotoxicity testing related to residual monomer. Aust. Dent. J. 44: 25-30.

Kricheldorf HR, Kreiser-Saunders I, Damrauet DK. 2000; Resorbable initiators for polymerizations of lactones. Macromol. Symp. 159: 247-58.

Kuboki Y, Jin Q and Takita H 2001; Geometry of Carriers Controlling Phenotypic Expression in BMP-Induced Osteogenesis and Chondrogenesis. J. Bone Joint. Surg. Am. 83: S105-S115.

Liow SS, Widjaja LK, Lipik VT et al. 2009; Synthesis, characterization and photopolymerization of vinyl functionalized poly ( $\varepsilon$-caprolactone). eXPRESS Polym. Lett. 3: 159-67.

Lu Y, Mapili G, Suhali G, Chen SC et al. 2006; A digital micro-mirror device-based system for the microfabrication of complex, spatially patterned tissue engineering scaffolds. J. Biomed. Mater. Res. A 77: 396-405.

Melchels FPW, Bertoldi K, Gabbrielli R et al. 2010; Mathematically defined tissue engineering scaffold architectures prepared by stereolithography. Biomaterials 31: 6909-16.

Melchels FPW, Feijen J, Grijpma DW. 2009; A poly(d,l-lactide) resin for the preparation of tissue engineering scaffolds by stereolithography. Biomaterials 30: 3801-09.

Melchels FPW, Feijen J, Grijpma DW. 2010; A review on stereolithography and its applications in biomedical engineering. Biomaterials 31: 6121-30.

Park SH, Park DS, Shin JW et al. 2012; Scaffolds for bone tissue engineering fabricated from two different materials by the rapid prototyping technique: PCL versus PLGA. $J$. Mater. Sci. Mater. Med. 23: 2671-78.

Pham DT, Gaul RS. 1998; A comparison of rapid prototyping technologies. Int. J. Mach. Tool. Manu. 38: 1257-87.

Rajagopalan S, Robb RA. 2006; Schwarz meets Schwann: Design and fabrication of biomorphic and durataxic tissue engineering scaffolds. Med. Image Anal. 10: 693-712.

Ronca A, Ambrosio L Grijpma DW. 2013; Preparation of designed poly(d,1lactide)/nanosized hydroxyapatite composite structures by stereolithography. Acta Biomaterialia 9: 5989-96.

Ronca A, Ambrosio L, Grijpma DW. 2012; Design of porous three-dimensional PDLLA/nano-hap composite scaffolds using stereolithography. J. Appl. Biomater. Funct. Mater. 10: 249-258.

Sawhney AS, Pathak CP, Hubbell JA. 1993; Bioerodible hydrogels based on photopolymerized poly(ethylene glycol)-co-poly( $\alpha$-hydroxy acid) diacrylate macromers. Macromolecules. 26: 581-87.

Storey RF, Warren SC, Allison CJ et al. 1993; Synthesis of bioabsorbable networks from methacrylate-endcapped polyesters. Polymer 34: 4365-72. 
Sun C, Fang N, Wu DM, Zhang X. 2005; Projection micro-stereolithography using digital micro-mirror dynamic mask. Sens. Actuators, A 121: 113-20.

Yang S, Leong KF, Du Z et al. 2001; The design of scaffolds for use in tissue engineering. I. Traditional factors. Tissue Eng. 7: 679-89.

Yeong WY, Chua CK, Leong KF. 2004; Rapid prototyping in tissue engineering: challenges and potential. Trends in Biotechnol 22: 643-52.

Yoo DJ. 2011; Computer-aided porous scaffold design for tissue engineering using triply periodic minimal surfaces. Int. J. Precis. Eng. Man. 12: 61-71.

Yoshii E. 1997; Cytotoxic effects of acrylates and methacrylates: Relationships of monomer structures and cytotoxicity. J. Biomed. Mater. Res. 37: 517-24. 
Tables

Table 1: molecular mass and Glass transition temperatures of Vinyl-PCL and divinyl fumarate PCL

\begin{tabular}{|c|c|c|c|c|c|c|}
\hline \multirow[t]{2}{*}{ Sample } & \multicolumn{2}{|c|}{ Ratio } & \multicolumn{3}{|c|}{ GPC } & \multirow{2}{*}{$\begin{array}{c}\text { DSC } \\
T_{\mathrm{m}}\end{array}$} \\
\hline & $\varepsilon-\mathrm{CL} / \mathrm{HEVE}$ & $\varepsilon-\mathrm{CL} / \mathrm{Al}$ & $M_{n}($ Theor $)$ & $M_{n}(G P C)$ & PDI & \\
\hline VPCL A & $50 / 1$ & $50 / 0.3$ & $6000 \mathrm{Da}$ & $6800 \times \mathrm{Da}$ & 1.3 & $53.5^{\#}$ \\
\hline VPCL B & $25 / 1$ & $25 / 0.3$ & $3000 \mathrm{Da}$ & $3900^{*} \mathrm{Da}$ & 1.5 & $52.4^{\#}$ \\
\hline VPCL C & $12.5 / 1$ & $12.5 / 0.3$ & $1500 \mathrm{Da}$ & $2400^{*} \mathrm{Da}$ & 1.3 & $50.8^{\#}$ \\
\hline VPCL F & - & - & $3000 \mathrm{Da}$ & $4400^{*} \mathrm{Da}$ & 1.9 & $52.6^{\#}$ \\
\hline
\end{tabular}

Table 2: Kinetic parameters for the photopolymerization of vinyl-PCL and divinyl fumarate PCL in NMP and NVP solution with 5 wt\% Lucirin TPO.

\begin{tabular}{l|cccccc}
\hline Sample & \multicolumn{2}{|c}{ Enthalpy (J/g) } & \multicolumn{2}{c}{ Peak maximum (s) } & \multicolumn{2}{c}{ Reacted at peak (\%) } \\
& NMP & NVP & NMP & NVP & NMP & NVP \\
\hline VPCL A & $7.2 \pm 1.3$ & $204.7 \pm 2.1$ & $0.58 \pm 0.02$ & $0.27 \pm 0.02$ & $21.30 \pm 3.75$ & $29.21 \pm 5.30$ \\
\hline VPCL B & $10.1 \pm 2.1$ & $207.8 \pm 4.0$ & $0.55 \pm 0.03$ & $0.28 \pm 0.02$ & $14.14 \pm 2.56$ & $33.76 \pm 1.41$ \\
\hline VPCL C & $9.4 \pm 1.7$ & $180.3 \pm 3.6$ & $0.53 \pm 0.02$ & $0.34 \pm 0.04$ & $18.33 \pm 3.89$ & $32.30 \pm 2.98$ \\
\hline VPCL F & $15.7 \pm 1.5$ & $208.1 \pm 9.5$ & $0.43 \pm 0.02$ & $0.25 \pm 0.02$ & $16.94 \pm 5.43$ & $25.55 \pm 3.88$ \\
\hline
\end{tabular}

Table 3: Results from $\mu \mathrm{CT}$ : comparison of structural parameters of the developed porous structures.

\begin{tabular}{c|cccc}
\hline Sample & & $\begin{array}{c}\text { Porosity } \\
(\%)\end{array}$ & $\begin{array}{c}\text { Specific surface area } \\
\left(\mathrm{mm}^{-1}\right)\end{array}$ & $\begin{array}{c}\text { Average pore size } \\
(\mu \mathrm{m})\end{array}$ \\
\hline \multirow{2}{*}{ Gyroid } & Built & $64.39 \pm 1.45$ & $9.06 \pm 1.2$ & $710 \pm 21$ \\
& CAD & 66.75 & 8.13 & - \\
\hline \multirow{2}{*}{ Diamond } & Built & $58.45 \pm 1.54$ & $9.40 \pm 1.4$ & $400 \pm 18$ \\
& CAD & 59.13 & 7.09 & - \\
\hline
\end{tabular}




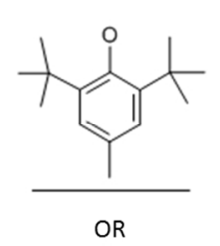

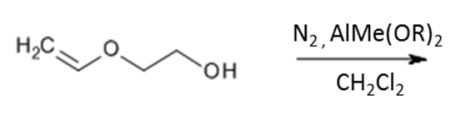

HEVE<smiles>C=COCCOC(=O)CCCCCO</smiles>

$\varepsilon$ - caprolactone
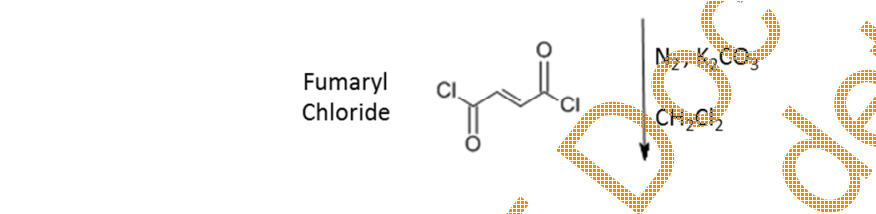

Chloride

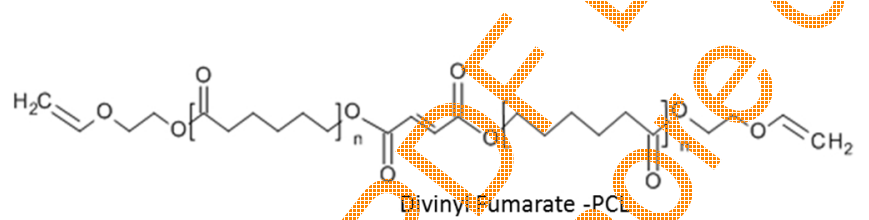

Divinyllfumarate - $P C$

Figure 1: General reaction scheme of the $\varepsilon$-caprolactone using HEVE as transfer agent and successive reaction with fumaryl chloride $105 \times 66 \mathrm{~mm}(300 \times 300 \mathrm{DPI})$ 


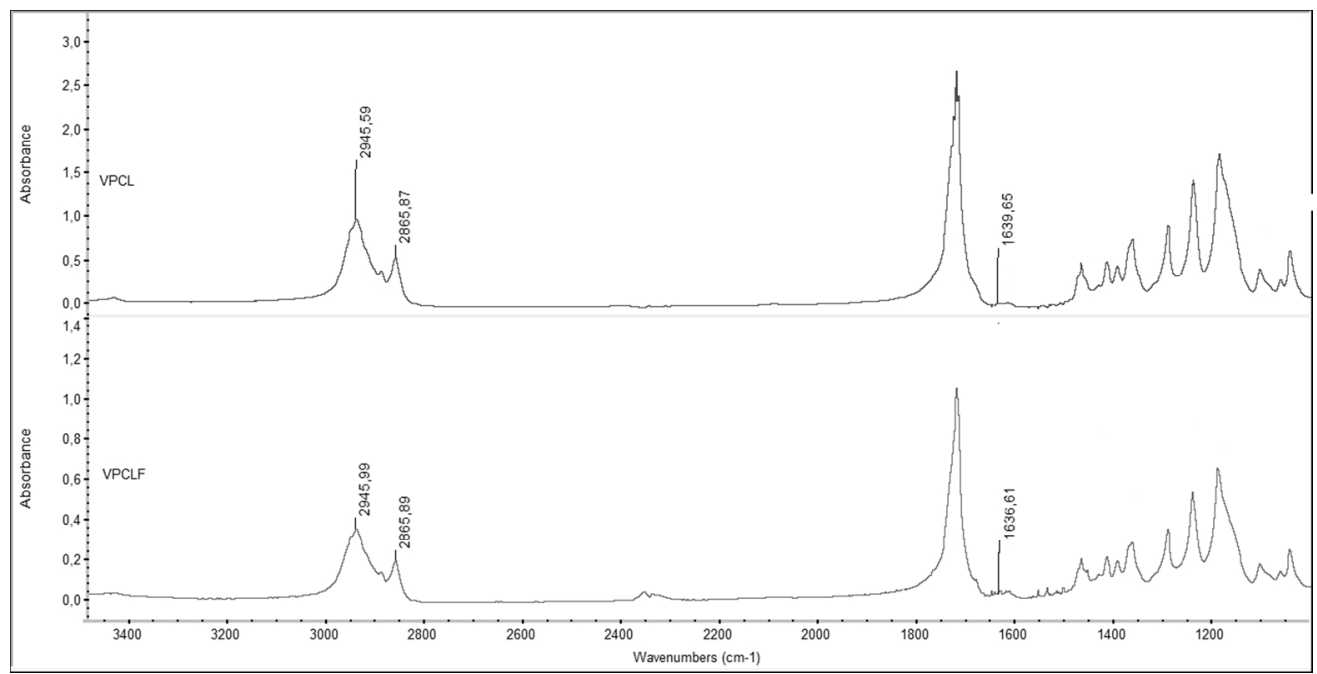

Figure 2: FTIR spectra of VPCL and VPCLF $107 \times 54 \mathrm{~mm}(300 \times 300 \mathrm{DPI})$ 
1

2

3

4

5

6

7

8

9

10

11

12

13

14

15

16

17

18

19

20

21

22

23

24

25

26

27

28

29

30

31

32

33

34

35

36

37

38

39

40

41

42

43

44

45

46

47

48

49

50

51

52

53

54

55

56

57

58

59

60

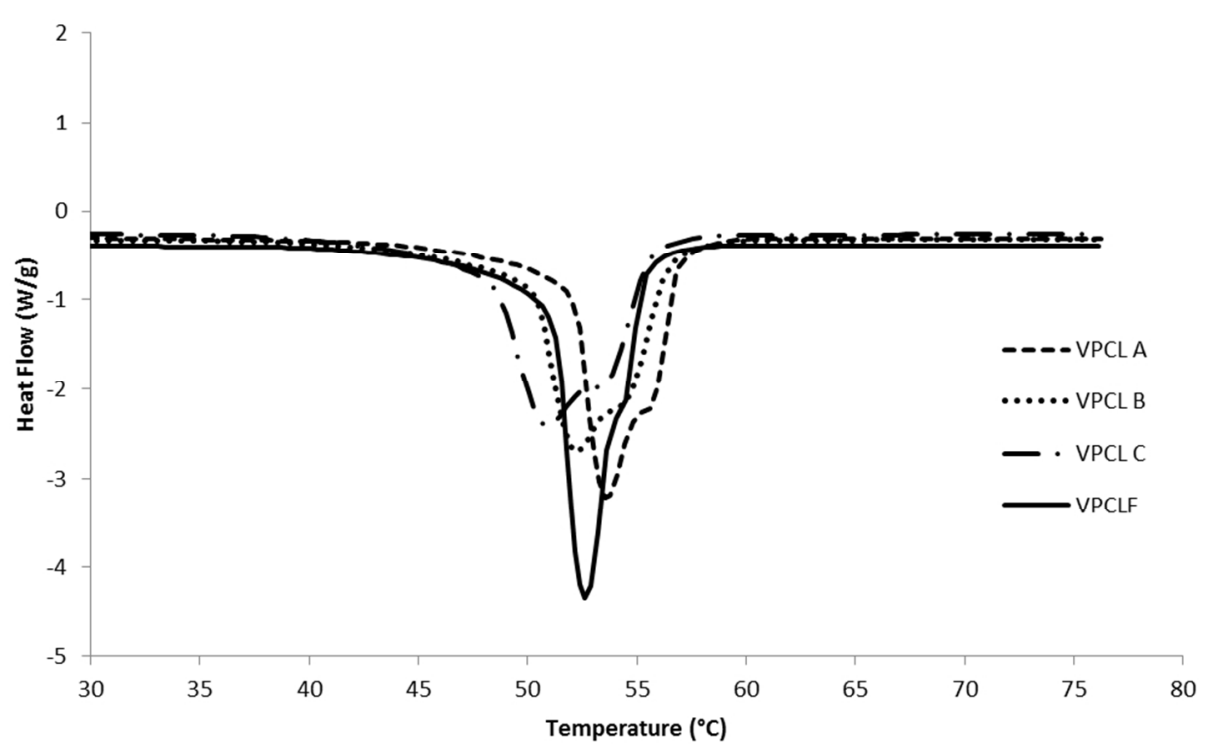

Figure 3: DSC thermograms of VPCL and VPCLF macromers $91 \times 53 \mathrm{~mm}(300 \times 300 \mathrm{DPI})$ 


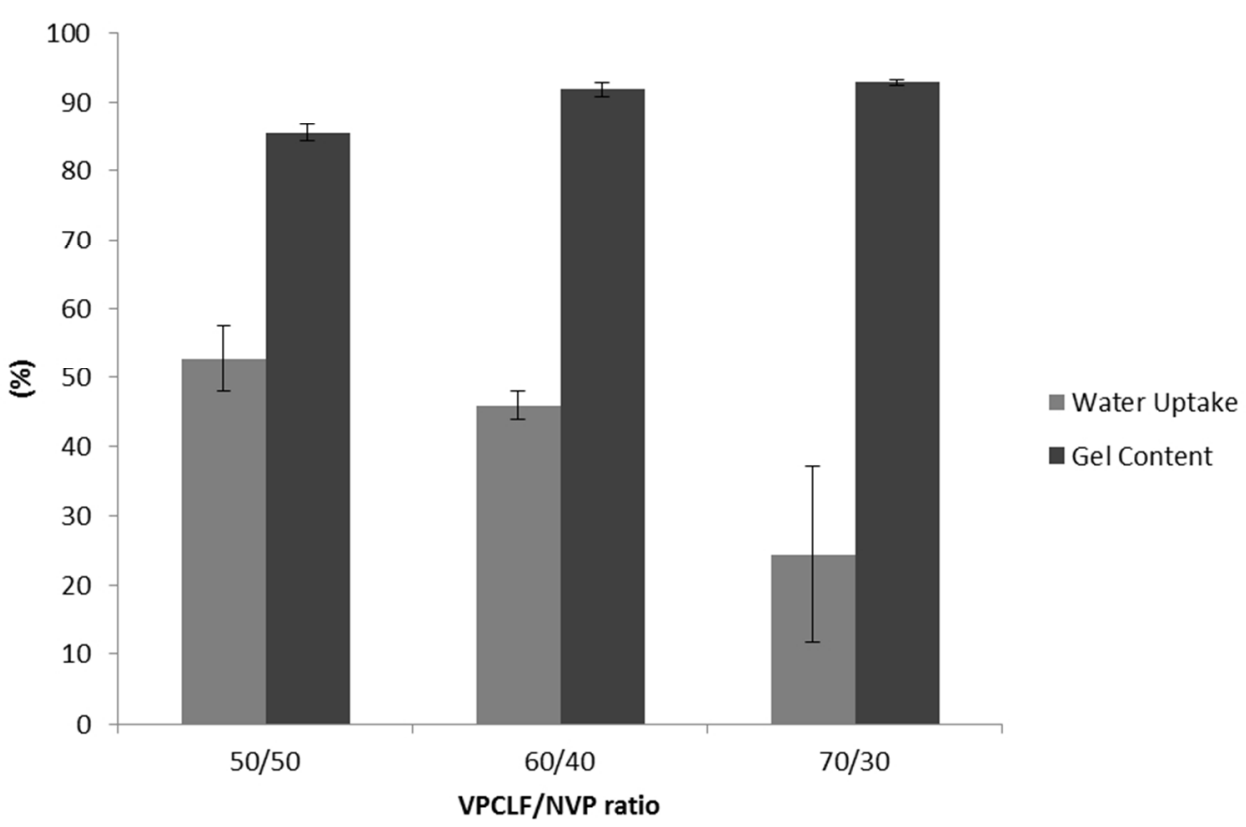

Figure 4: Water uptake and gel content for crosslinked sample at different VPCLF/NVP ratio $78 \times 51 \mathrm{~mm}(300 \times 300 \mathrm{DPI})$ 


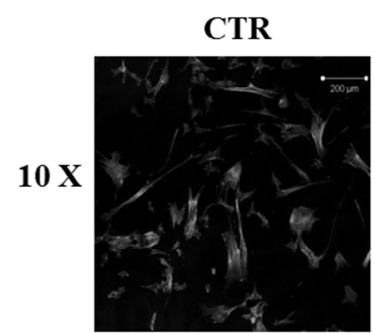

$\mathbf{5 0 / 5 0}$
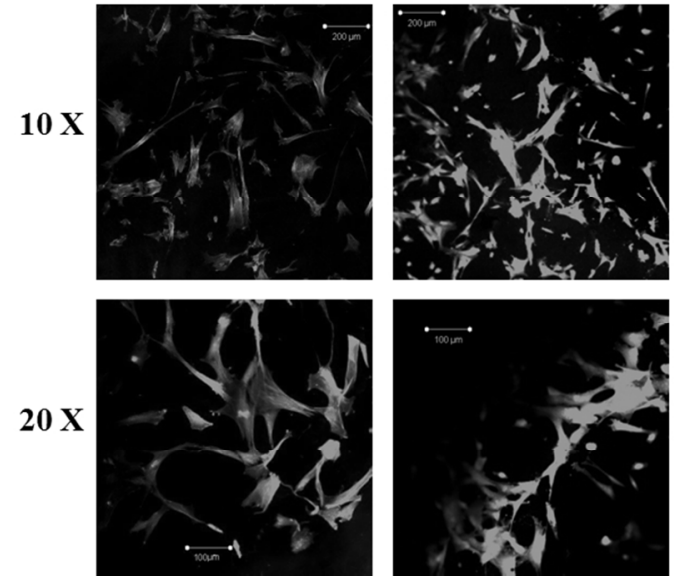

$60 / 40$
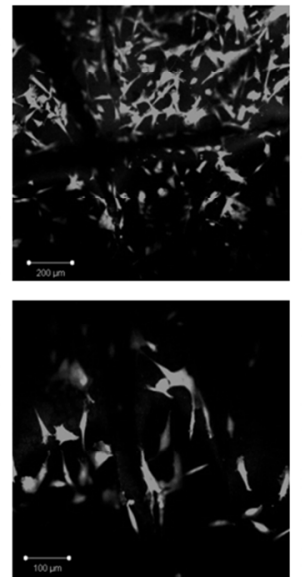

70/30
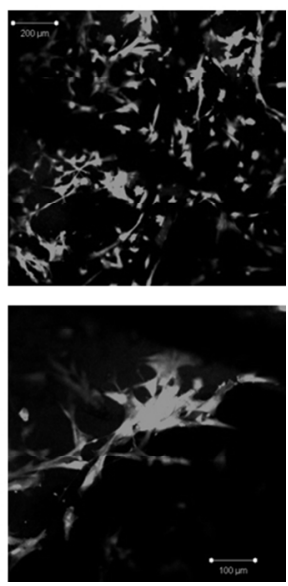

Figure 4: Confocal images of hMSCs adhesion and cell material-interaction on VPCLF/NVP rounded sample and tissue culture polystyrene (CTR) after culturing for $24 \mathrm{~h}$ $97 \times 46 \mathrm{~mm}(300 \times 300 \mathrm{DPI})$ 
Figure 6: Viability of hMSCs on VPLCF/NVP specimens (Alamar Blue assay). Control: tissue culture polystyrene (negative control).

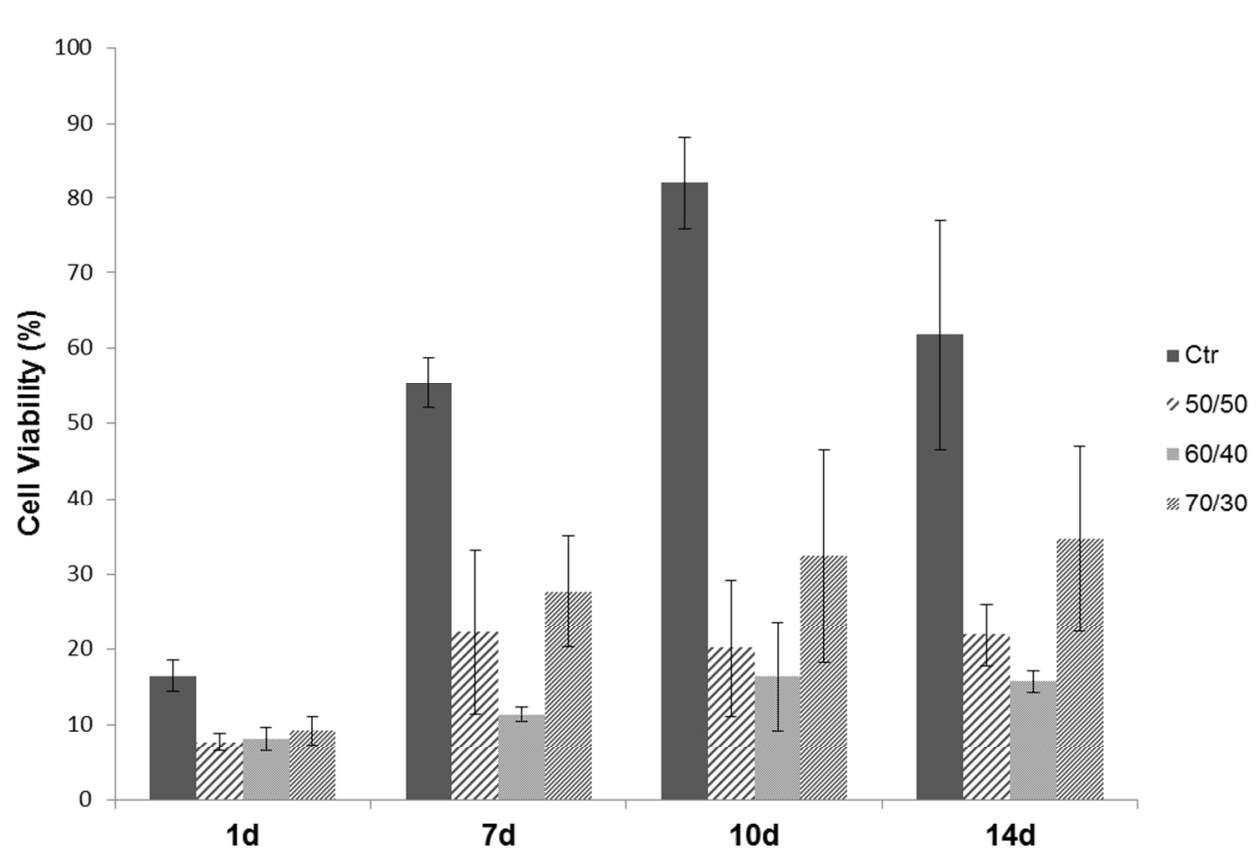

$92 \times 59 \mathrm{~mm}(300 \times 300$ DPI $)$ 
Figure 7: SEM analysis on structures obtained by stereolithography from VPCLF/NVP resin: images of porous structures with Gyroid (G) and Diamond (D) primitive pore network architecture $124 \times 57 \mathrm{~mm}(300 \times 300 \mathrm{DPI})$ 

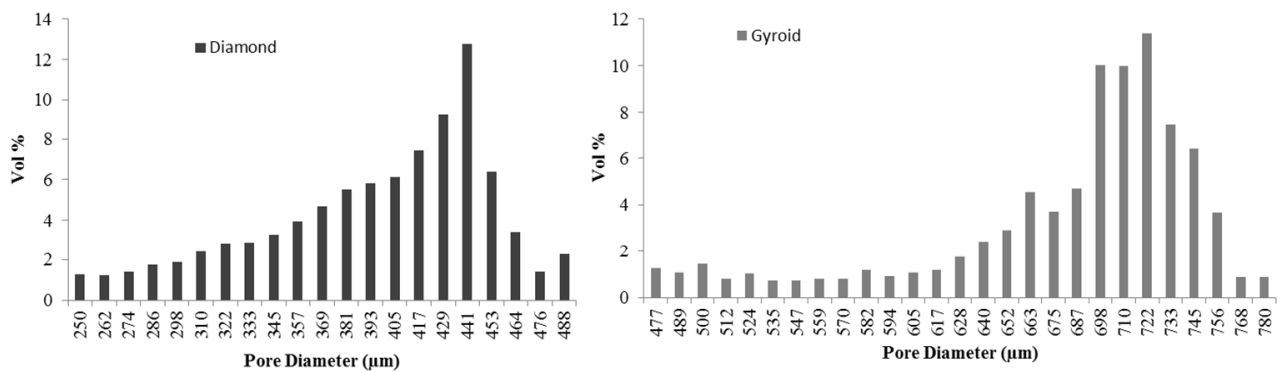

Figure 8: Pore size distribution for Diamond and Gyroid built structures $125 \times 35 \mathrm{~mm}(300 \times 300 \mathrm{DPI})$ 